\title{
Oxidative stress-induced poly(ADP-ribosyl)ation in chick limb bud-derived chondrocytes
}

\author{
RÓZA ZÁKÁNY ${ }^{*}$, EDINA BAKONDI ${ }^{2 *}$, TAMÁS JUHÁSZ1 ${ }^{1}$, CSABA MATTA $^{1}$, ZSOLT SZÍJGYÁRTÓ2 $^{2}$ \\ KATALIN ERDÉLYI ${ }^{2,4}$, ÉVA SZABÓ ${ }^{3}$, LÁSZLÓ MÓDIS ${ }^{1}$, LÁSZLÓ VIRÁG ${ }^{2}$ and PÁL GERGELY ${ }^{2,4}$ \\ Departments of ${ }^{1}$ Anatomy, Histology and Embryology, ${ }^{2}$ Medical Chemistry, ${ }^{3}$ Dermatology, Research Center \\ for Molecular Medicine, Medical and Health Science Center, University of Debrecen, Debrecen; \\ ${ }^{4}$ Cell Biology and Signalling Research Group of the Hungarian Academy of Sciences, Hungary
}

Received November 14, 2006; Accepted December 22, 2006

\begin{abstract}
Oxidative stress has been implicated in the pathogenesis of various diseases affecting chondrogenesis or the function of articular cartilage. DNA damage caused by oxidative stress may trigger the activation of the nuclear enzyme, poly(ADP-ribose) polymerase-1 (PARP-1) which may contribute to tissue injury. We aimed at investigating the effects of peroxynitrite (100-600 $\mu \mathrm{M})$ and hydrogen peroxide (0.1-4 mM) on PARP activation and extracellular matrix production of high density micromass cultures (HDC) prepared from chick limb bud mesenchymal cells. We found that both oxidative species strongly inhibited matrix formation of HDCs treated on day 2 but not on day 5. The PARP inhibitor 3-aminobenzamide (3-AB) stimulated matrix production in non-stressed cells and prevented suppressed matrix production in oxidatively stressed cells. Both hydrogen peroxide and peroxynitrite induced PARP activation and poly(ADP-ribose) accumulation. Decreased proliferation, viability and $\mathrm{NAD}^{+}$content were not or only slightly improved by $3-A B$, indicating that $3-A B$ directly affects matrix formation. In conclusion, oxidative stress stimulates poly(ADP-ribose) metabolism and inhibits extracellular matrix production of HDCs in a PARP-dependent manner. Our findings may have implications for potential therapeutic approaches aimed at restoring the matrix production capacity of chondrogenic cells.
\end{abstract}

Correspondence to: Dr Pál Gergely, Department of Medical Chemistry, Medical and Health Science Center, University of Debrecen, 4032 Debrecen, Egyetem tér 1, Hungary

E-mail: gpal@dote.hu

${ }^{*}$ Contributed equally

Key words: poly(ADP-ribosyl)ation, oxidative stress, peroxynitrite, extracellular matrix, chondrocyte

\section{Introduction}

During embryonic development or during growth of tubular bones, chondrogenic mesenchymal cells and chondrocytes undergo proliferation followed by initiation of a tightly controlled developmental program leading to terminal differentiation (1-3). This process is accompanied by characteristic changes in phenotype including a switch from the expression of type I to type II collagen, appearance of type X collagen, release and mineralization of matrix vesicles, increase in alkaline phosphatase activity and expression of vitamin D receptors.

Primary cell culture established from chondrogenic mesenchymal cells isolated from chick limb buds is a wellknown and widely used experimental model for investigation of cartilage differentiation. Chondrogenic cells must be inoculated in a very high density (15-20 million cells per milliliter) to gain appropriate cartilage formation. In such high-density micromass cell cultures of chondroprogenitor mesenchymal cells, a spontaneous cartilage formation occurs within 6 days $(4,5)$. The differentiation process starts with condensation of chondrogenic cells and is followed by development of precartilage nodules. The cells of these nodules establish cell-to-cell contacts, and differentiate into mature chondrocytes under the control of paracrine and endocrine signals $(1,6)$. In micromass cultures, the major steps of cartilage differentiation occur on days 2 and 3 when young cartilage cells start to secrete a specific extracellular matrix rich in type II collagen and aggrecan $(2,3)$.

Differentiation, survival and maintenance of the chondrocyte phenotype are regulated by various physical and soluble factors (2). Among these factors, oxidative stress agents including reactive oxygen- and nitrogen-containing intermediates (ROI and RNI, respectively) have also been shown to affect development and homeostasis of the cartilage. Chondrocytes produce superoxide, hydrogen peroxide and hydroxyl radicals (ROI species) under resting condition or after immune stimulation (7-10). Moreover, nitric oxide (the primary RNI species) has also been shown to be produced during chondrogenesis and in osteoarthritis (11-13). Increased production of reactive species has been proposed to contribute to the pathology observed in inflammatory joint diseases 
(14-17). The deleterious effects of reactive species in the cartilage range from inhibition of proliferation, suppression of synthesis and induction of degradation of matrix components to triggering cell death. Peroxynitrite, a highly reactive intermediate formed in the diffusion-limited reaction of nitric oxide and superoxide (18) has also been implicated in the dysfunction and cell death of chondrocytes (19). Peroxynitrite can damage cells by a complex mechanism including protein oxidation and nitration, lipid peroxidation and DNA damage $(20,21)$. In addition to the direct damaging effects, peroxynitrite-induced DNA damage is known to trigger intense enzymatic poly(ADP-ribose) synthesis from $\mathrm{NAD}^{+}$ (20). Depletion of $\mathrm{NAD}^{+}$and consequently ATP by poly(ADP-ribose) polymerase-1 (PARP-1), a DNA nick sensor enzyme, has been shown to cause cell dysfunction, apoptotic or necrotic cell death (22). Although sporadic data indicate that poly(ADP-ribosyl)ation may regulate chondrocyte development and function (23-26), oxidative stressinduced poly(ADP-ribosyl)ation has not yet been investigated in chondrogenic cells and chondrocytes.

Therefore, the aim of this study was to investigate the role of poly(ADP-ribosyl)ation in oxidative stress-induced dysfunction and cytotoxicity of chondrogenic cells. We chose hydrogen peroxide and peroxynitrite as two pathophysiologically relevant oxidative stress species to induce poly(ADP-ribosyl)ation. Here we provided evidence for the activation of PARP-1 in oxidatively stressed chondrocytes. Moreover, we demonstrated that increased PARP activity plays a role in the inhibition of cartilage formation of oxidatively stressed HDCs.

\section{Materials and methods}

Cell culture. Distal parts of the limb buds of Ross hybrid chicken embryos of Hamburger-Hamilton stages 22-24 were removed and primary micromass cultures of chondrifying mesenchymal cells were established from cell suspensions with a density of $15 \times 10^{6}$ cells $/ \mathrm{ml}(4,5,27)$. Droplets of the suspension (30-30 $\mu \mathrm{l})$ were inoculated onto glass coverslips (Menzel-Gläser, Menzel GmbH, Braunschweig, Germany) and placed into the wells of 24-well cell culture plates (Nunc, Roskilde, Denmark). Colonies were nourished with Ham's F12 medium (Sigma-Aldrich, Budapest, Hungary), supplemented with $10 \%$ fetal calf serum (Gibco, Gaithersburg, MD, USA) and kept at $37^{\circ} \mathrm{C}$ in the presence of $5 \% \mathrm{CO}_{2}$ and $95 \%$ humidity in a $\mathrm{CO}_{2}$ incubator. The medium was changed every second day or after the hydrogen peroxide or peroxynitrite treatments.

For the generation of oxidative stress, 2-day-old highdensity cell cultures were treated with variable concentrations of $\mathrm{H}_{2} \mathrm{O}_{2}(0.1,1.0$ or $4.0 \mathrm{mM})$ or peroxynitrite $(100,300$ or $600 \mu \mathrm{M}$ ) for $30 \mathrm{~min} . \mathrm{H}_{2} \mathrm{O}_{2}$ was diluted with sterile distilled water from a $9 \mathrm{M}$ stock solution (Sigma-Aldrich). Peroxynitrite solution was purchased from Calbiochem (San Diego, $\mathrm{CA}$ ) and was kept at $-80^{\circ} \mathrm{C}$. Peroxynitrite was diluted in alkaline ( $\mathrm{pH} 12.0$ ) saline solution and was added to micromass cultures in $50 \mu \mathrm{l}$ volume. Decomposed peroxynitrite (incubated for $30 \mathrm{~min}$ at $\mathrm{pH}$ 7.0) served as a control.

In order to inhibit PARP activity, $5 \mathrm{mM} 3$-aminobenzamide (3-AB) (Sigma-Aldrich) was added to the culture medium 30 min prior to the oxidative stress.
Light microscopic analysis of cartilage formation in highdensity cultures. Relative efficiency of the cartilage formation was estimated by the analysis of metachromasia based on the dimethylmethylene blue staining of glycosaminoglycan (GAG) components of the proteoglycan molecules of cartilage matrix (28). High-density cultures of different experimental groups were fixed in a 4:1 mixture of absolute ethanol and $40 \%$ formaldehyde on day 6 of culturing. Cultures were stained with $0.1 \%$ dimethylmethylene blue (DMMB, SigmaAldrich) dissolved in 3\% acetic acid, washed in acetic acid and mounted in gum arabic (28). Under these conditions, only the sulphated GAG components of the cartilage matrix stained to yield a purple color. The size of the metachromatic cartilaginous areas was measured in 5 cultures of each experimental group in 4 independent experiments by computer-assisted image analysis as described previously (29).

Measurement of cell proliferation. Cell proliferation was determined by $\left[{ }^{3} \mathrm{H}\right]$ thymidine incorporation as described (29). Droplets of cell suspension $(15 \mu \mathrm{l})$ were inoculated into the wells of 96-well microtiter plates, and the cells were treated similarly to those cultured in the 24-well plates. Medium containing $1 \mu \mathrm{Ci} / \mathrm{ml}\left[{ }^{3} \mathrm{H}\right]$ thymidine (diluted from methyl- $\left[{ }^{3} \mathrm{H}\right]$ thymidine solution; Amersham Pharmacia Biotech., UK) was added to the wells and cultures were incubated for $16 \mathrm{~h}$. After washing with PBS, proteins were precipitated with ice-cold $5 \%$ trichloroacetic acid, washed with PBS again, digested with $0.25 \%$ trypsin dissolved in calcium magnesium-free phosphate-buffered saline and harvested with a semiautomatic cell-harvester (Skatron, Norway). Harvested colonies were dried on scintillation filter paper, and the radioactivity was measured with a B-counter (Pharmacia, Sweden). Measurements were carried out in 10 samples of each experimental group in 4 independent experiments.

Determination of cellular viability in HDCs. Viability of cells was tested with MTT assay (30). Droplets of cell suspension $(15 \mu \mathrm{l})$ were inoculated into wells of 96-well microtiter plates, and the cells were treated similarly to those cultured in the 24-well plates. Following treatments with $\mathrm{H}_{2} \mathrm{O}_{2}$ or peroxynitrite, cells were washed twice with PBS, and $10 \mu \mathrm{l}$ of 3-[4,5-dimethylthiazol-2-yl]-2,5-diphenyl-tetrazolium bromide (MTT reagent, final concentration of $0.5 \mathrm{mg} / \mathrm{ml}$ ) was pipetted into each well, and the cells were incubated for $2 \mathrm{~h}$ in a $\mathrm{CO}_{2}$ incubator. After incubation, 100-600 $\mu \mathrm{l}$ of MTT-solubilizing solution (10\% Triton X-100 and 0.1 M $\mathrm{HCl}$ dissolved in isopropanol) was added to each well. After gentle shaking, the absorbance was determined by a Multiskan MS plate reader (Labsystem, Vantaa, Finland) at $540 \mathrm{~nm}$.

Immunocytochemical detection of poly(ADP-ribose). Poly(ADP-ribose) was detected by immunocytochemistry, as described by Bürkle et al (31) with slight modifications as follows. Cells were fixed in ice-cold $10 \%$ trichloroacetic acid for $3 \mathrm{~min}$ at $-20^{\circ} \mathrm{C}$ and for an additional $1 \mathrm{~h}$ in St. Mary solution (96\% ethanol:100\% acetic acid, 99:1) at $4^{\circ} \mathrm{C}$. After rehydration in PBS (5 min at room temperature) coverslips were blocked in $5 \%$ horse serum (Vector Laboratories, 
Burlingame, CA, USA) diluted in phosphate-buffered saline (PBS)-Triton $\mathrm{X}-100$ for $1 \mathrm{~h}$ and were then incubated overnight at $4^{\circ} \mathrm{C}$ with monoclonal anti-poly(ADP-ribose) antibody diluted 1:300. After five 5-min washes in PBS, coverslips were incubated with biotinylated horse anti-mouse immunoglobulin G (Vector Laboratories) diluted 1:300 for $45 \mathrm{~min}$ at room temperature. Excess antibody was removed by five 5-min washes in PBS-Triton X-100, and the bound antibody was visualized by streptavidin-AlexaFluor-546 (Molecular Probes, Eugene, OR, USA) diluted 1:100 in PBS-Triton X-100 (30 min at room temperature). Nuclei were stained by DAPI ( $1 \mu \mathrm{g} / \mathrm{ml} \mathrm{PBS-Triton} \mathrm{X-100} \mathrm{for} 30 \mathrm{~min}$ at room temperature). Coverslips were washed 4 times ( 5 min each time) with PBSTriton X-100, mounted in anti-fade medium and viewed with a Zeiss Axiolab microscope. Pictures were taken with a Zeiss Axiocam digital camera. Images of immunofluorescence and DAPI staining were overlaid using Adobe ${ }^{\circledR}$ Photoshop software.

In situ detection of PARP activity. PARP activity was detected by an in situ enzyme cytofluorescent method as previously published (32). The culture medium was replaced with PARP reaction buffer [56 mM HEPES, $28 \mathrm{mM} \mathrm{KCl,} 28 \mathrm{mM} \mathrm{NaCl}$, $2 \mathrm{mM} \mathrm{MgCl}_{2}, \mathrm{pH} 8.0$ complemented with $0.01 \%$ digitonin, and $12.5 \mu \mathrm{M}$ biotinylated NAD ${ }^{+}$(R\&D Systems, Minneapolis, $\mathrm{MN}$, USA)]. After a 60 -min incubation at $37^{\circ} \mathrm{C}$, the cells were fixed in $95 \%$ ethanol $\left(10 \mathrm{~min}\right.$ at $\left.-20^{\circ} \mathrm{C}\right)$ followed by incubation in ice-cold $10 \%$ trichloroacetic acid for $10 \mathrm{~min}$. Cells were dehydrated by successive 5 -min washes in $70 \%$, $90 \%$, and $100 \%$ ethanol at $-20^{\circ} \mathrm{C}$. After three 5-min rinses with PBS, coverslips were blocked in $1 \%$ bovine serum albumin (BSA) in PBS for 30 min followed by two rinses in PBS-Triton X-100 (0.1\%). Incorporated biotin was detected by streptavidin-AlexaFluor-546 diluted 1:100 in PBS-Triton $\mathrm{X}-100$ (30 min at room temperature). Nuclear staining and further steps were carried out as described above.

Measurement of cellular $\mathrm{NAD}^{+}$content. The cellular $\mathrm{NAD}^{+}$ content was determined with the recycling assay as previously described (33) with minor modifications. Cells were extracted in $0.5 \mathrm{~N} \mathrm{HClO}_{4}$, neutralized with $3 \mathrm{M} \mathrm{KOH} / 125 \mathrm{mM}$ Gly-Gly buffer ( $\mathrm{pH} 7.4$ ), and centrifuged at $10000 \mathrm{x} \mathrm{g}$ for 5 min. Supernatants were mixed with a reaction medium containing $0.1 \mathrm{mM}$ MTT, $0.9 \mathrm{mM}$ phenazine methosulfate, $13 \mathrm{U} / \mathrm{ml}$ alcohol dehydrogenase, $100 \mathrm{mM}$ nicotinamide, and $5.7 \%$ ethanol in $61 \mathrm{mM}$ Gly-Gly buffer $\left(\mathrm{pH}\right.$ 7.4). The $\mathrm{A}_{560 \mathrm{~nm}}$ was determined immediately and after $10 \mathrm{~min}$. $\mathrm{NAD}^{+}$levels were calculated from a standard curve generated with known concentrations of $\mathrm{NAD}^{+}$.

\section{Results}

Oxidative stress-induced PARP activation contributes to suppression of matrix production. Effect of oxidative stress on cartilage formation and matrix production was visualized by DMMB staining of 6-day HDCs which were exposed to the oxidants on days 2 and 5 of culture. In HDCs treated on day 2 , peroxynitrite or hydrogen peroxide inhibited the formation of cartilage in a concentration-dependent manner (Figs. 1 and 2). At a $4-\mathrm{mM}$ concentration, $\mathrm{H}_{2} \mathrm{O}_{2}$ almost totally blocked chondrogenesis, since the average of the DMMBpositive matrix areas was only $4 \%$ of the untreated controls (Fig. 1). Similar results were obtained with peroxynitrite (Fig. 2). In order to determine whether poly(ADP-ribosyl)ation played a role in the suppression of matrix production, we used 3-aminobenzamide (3-AB) an inhibitor of PARP enzymes. $3-\mathrm{AB}$ was administered to the cells either as a short pretreatment (starting $30 \mathrm{~min}$ prior to and then washed out immediately before oxidant exposure) or as a continuous treatment (also starting $30 \mathrm{~min}$ prior to administration of the oxidant but not washed out). Short pretreatment with $3-\mathrm{AB}$ provided considerable protection against peroxynitrite- or hydrogen peroxide-induced inhibition of matrix formation (Figs. 1 and 2). Under conditions when 3-AB was present in the culture medium from day 2 until the end of culture (day 6) a substantial increase in matrix formation was observed both with and without oxidative stress treatment (not shown). These data indicate that poly(ADP-ribosyl)ation is a negative regulator of matrix synthesis under resting condition and that oxidative stress-induced poly(ADP-ribosyl)ation may also contribute to the suppression of matrix synthesis. Older (5-day-old) cultures proved less sensitive against oxidative stress and responded to peroxynitrite and hydrogen peroxide with slightly reduced or unchanged matrix production (Figs. 1 and 2).

Effect of oxidative stress on the proliferation and viability of $H D C$ cells. In order to learn whether the oxidative stressinduced inhibition on matrix mass in HDCs results from slower proliferation or from cell death we measured these parameters in oxidatively stressed HDCs (Fig. 3). Both peroxynitrite and hydrogen peroxide caused a concentrationdependent inhibition of cell proliferation, as measured by tritiated thymidine incorporation. Pretreatment of the cultures with $3-\mathrm{AB}$ had no major effect on proliferation although the inhibitory effect of $600 \mu \mathrm{M}$ of peroxynitrite was slightly but significantly prevented by $3-\mathrm{AB}$ (Fig. $3 \mathrm{~A}$ and $\mathrm{B}$ ). We also determined the viability of the cells by MTT reduction. We observed that, as compared to proliferation assays, higher concentrations of the oxidants were required to cause decreased viability (Fig. 3C and D). PARP inhibition by 3-AB provided significant protection against peroxynitrite. Slight but statistically significant protection by $3-\mathrm{AB}$ was observed in HDCs exposed to hydrogen peroxide. These data indicate that whereas a low degree of oxidative stress inhibits cell proliferation by a poly(ADP-ribosyl)ation-independent mechanism, intense oxidative stress, especially peroxynitrite causes cytotoxicity mediated, at least in part, by poly(ADPribosyl)ation. As PARP-mediated cell death is often accompanied by depletion of $\mathrm{NAD}^{+}$the substrate of PARPs, we determined cellular $\mathrm{NAD}^{+}$levels in oxidatively stressed HDCs (Fig. 3E and F). Surprisingly, only the highest concentration $(600 \mu \mathrm{M})$ of peroxynitrite resulted in notable $\mathrm{NAD}^{+}$depletion which could not be significantly inhibited by 3-AB. Hydrogen peroxide, on the other hand, caused only a marginal depletion of cellular $\mathrm{NAD}^{+}$content which was partially preventable by $3-\mathrm{AB}$.

Oxidative stress-induced PARP activation in HDC cells. As both peroxynitrite and hydrogen peroxide are known to cause 
Treated on Day 2

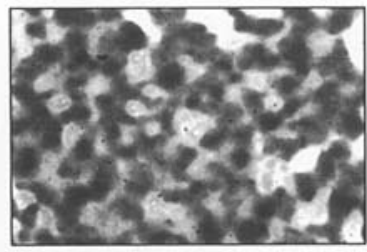

control $(100 \%)$

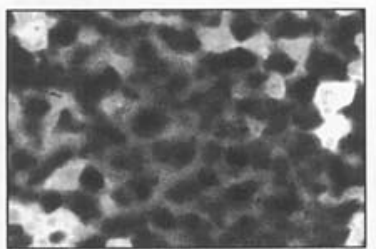

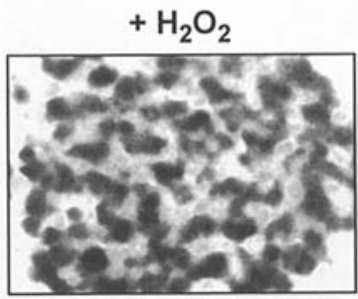

$0.1 \mathrm{mM}(87 \%)$

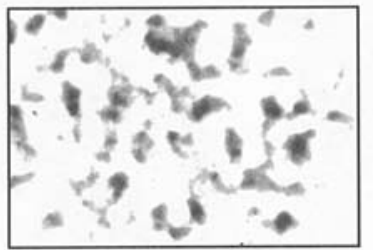

$1 \mathrm{mM}(16 \%)$

$+\mathrm{H}_{2} \mathrm{O}_{2}+5 \mathrm{mM} 3 \mathrm{AB}$

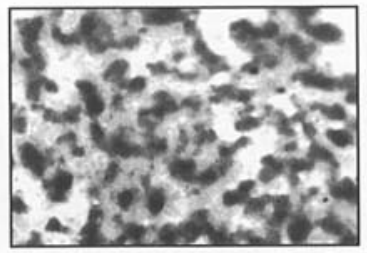

$0.1 \mathrm{mM}(85 \%)$

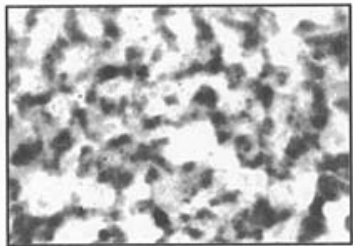

$1 \mathrm{mM}(58 \%)$

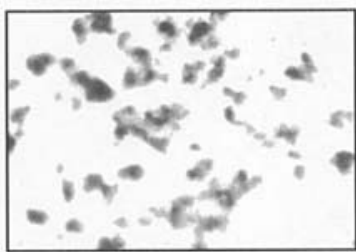

Treated on Day 5

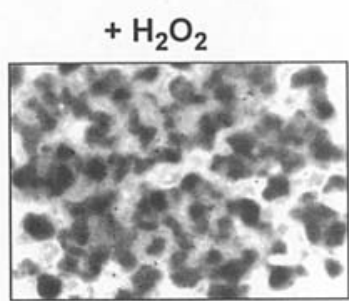

$0.1 \mathrm{mM}(81 \%)$

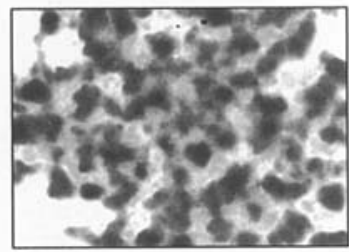

$1 \mathrm{mM}(76 \%)$
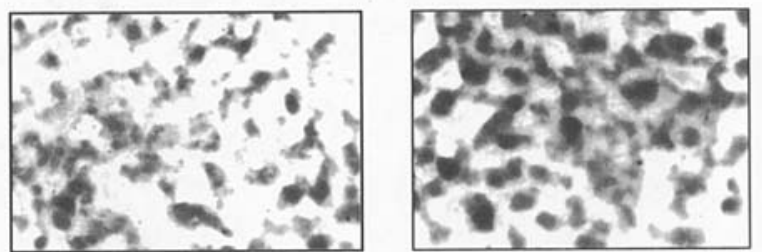

Figure 1. Effect of hydrogen peroxide on the formation of metachromatic cartilage areas. $\mathrm{HDCs}$ were treated with the indicated concentrations of $\mathrm{H}_{2} \mathrm{O}_{2}$ either on day 2 or 5 of culture, with or without 3 -amino-benzamide (3-AB) pretreatment. On day 6 , the size of the metachromatic cartilaginous areas was determined by DMMB staining and was quantified by computer-assisted image analysis ( 5 cultures from each experimental group in 4 independent experiments). Representative pictures of one experiment are shown. Numbers indicate relative size of cartilage areas (average values of each experimental group of 20 measurements from 4 independent experiments).

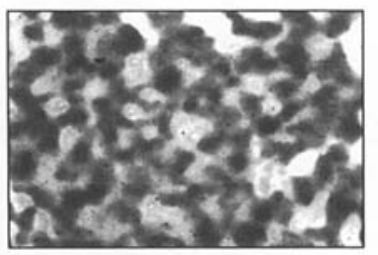

control $(100 \%)$

\section{Treated on Day 2}

+ peroxynitrite

+ peroxynitrite

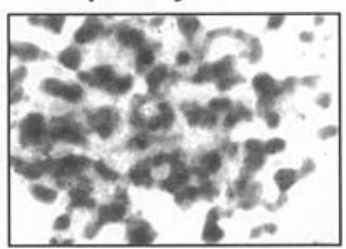

$100 \mu \mathrm{M}(62 \%)$

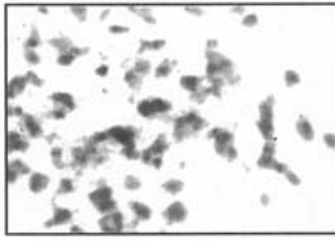

$300 \mu \mathrm{M}(13 \%)$

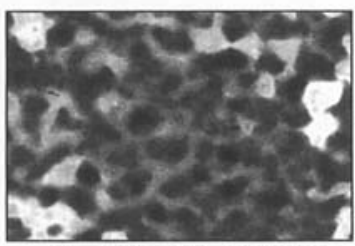

+ $5 \mathrm{mM} 3 \mathrm{AB}(145 \%)$

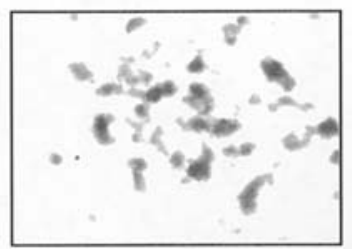

$600 \mu \mathrm{M}(5 \%)$
+5 mM 3AB

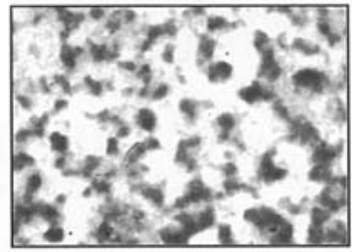

$100 \mu \mathrm{M}(68 \%)$

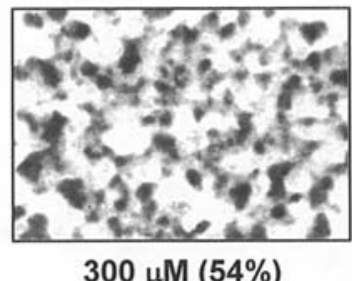

$300 \mu \mathrm{M}(54 \%)$

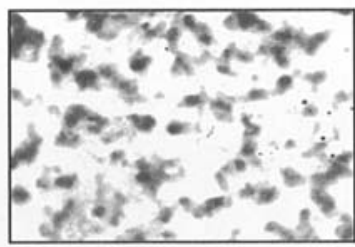

$600 \mu \mathrm{M}(31 \%)$
Treated on Day 5

+ peroxynitrite

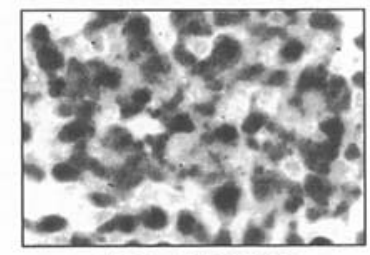

$100 \mu \mathrm{M}(81 \%)$

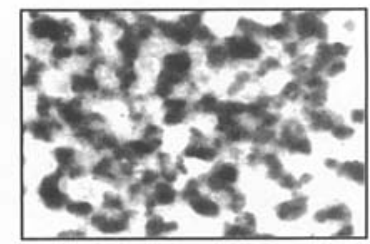

$300 \mu \mathrm{M}(63 \%)$

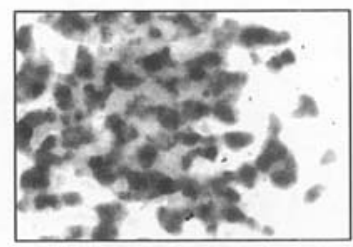

$600 \mu \mathrm{M}(59 \%)$

Figure 2. Effect of peroxynitrite on the formation of metachromatic cartilage areas. HDCs were treated with the indicated concentrations of peroxynitrite either on day 2 or 5 of culturing, with or without 3 -amino-benzamide (3-AB) pretreatment. On day 6 , the size of the metachromatic cartilaginous areas was determined by DMMB staining and was quantified by computer-assisted image analysis ( 5 cultures from each experimental group in 4 independent experiments). Representative pictures of one experiment are shown. Numbers indicate relative size of cartilage areas (average values of each experimental group of 20 measurements from 4 independent experiments). 

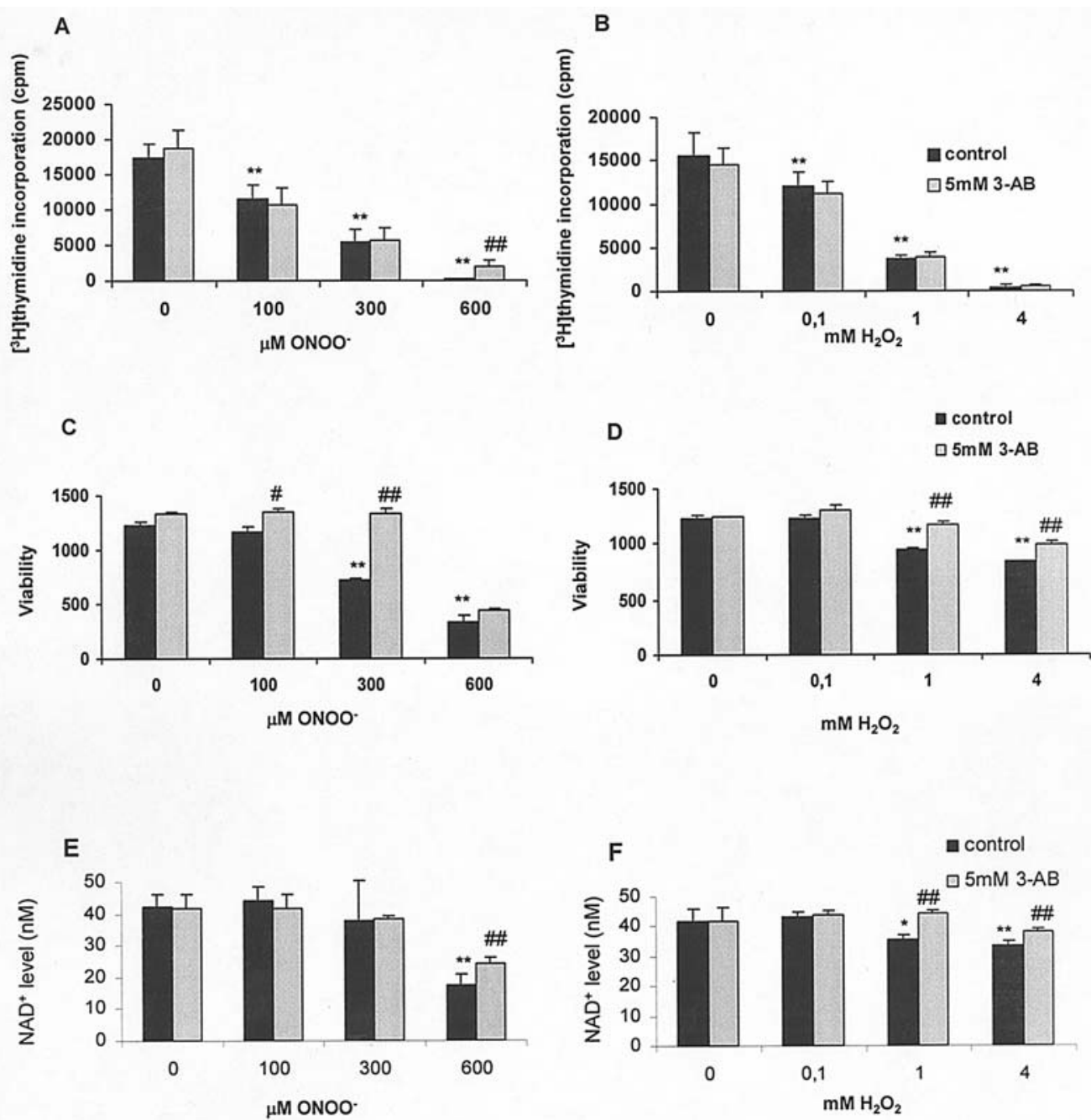

Figure 3. Effect of oxidative stress on proliferation, viability and NAD level of HDCs. HDCs were exposed to the indicated concentrations of peroxynitrite $(A, C, E)$ or hydrogen peroxide $(B, D, F)$ with or without pretreatment [5 mM 3-aminobenzamide (3-AB), 30 min]. Proliferation $(A, B)$ and cytotoxicity $(C, D)$ were assessed after $4 \mathrm{~h}$ by $\left[{ }^{3} \mathrm{H}\right]$-thymidine incorporation and MTT assay, respectively. Data represent mean \pm standard error of the mean of three independent experiments. The effect of oxidative stress on the intracellular $\mathrm{NAD}^{+}$levels was also determined 90 min following oxidant treatments (E, F). Data represent mean \pm standard error of the mean of three independent experiments. Asterisks indicate significant $\left({ }^{*} \mathrm{P}<0.05 ;{ }^{* *} \mathrm{P}<0.01\right)$ decrease in proliferation, viability or $\mathrm{NAD}^{+}$content as compared to control. The statistical significance of the protective effect of $3-\mathrm{AB}$ as compared to the oxidatively stressed HDCs are indicated $\left(" \mathrm{P}<0.05 ;{ }^{\#} \mathrm{P}<0.01\right)$.

DNA damage and to induce PARP activation (34), we detected PARP activation in oxidatively stressed HDCs. PARP activity was detected by an in situ enzyme activity assay based on the incorporation of biotin from biotinylated $\mathrm{NAD}^{+}$into the cellular protein of unfixed permeabilized cells. With this technique we detected no PARP activity in resting HDCs (Fig. 4). However, both peroxynitrite and, to a lesser extent, hydrogen peroxide stimulated nuclear biotin incorporation in HDCs. Pretreatment of HDCs with 3-AB abolished biotin incorporation from $\mathrm{NAD}^{+}$indicating that PARP was indeed responsible for the biotin incorporating activity. Moreover, we also detected poly(ADP-ribose) (PAR), the polymer product of the PARP-catalyzed reaction (Fig. 5). With a monoclonal anti-poly(ADP-ribose) antibody we found poly(ADP-ribose) in the nucleoli of untreated HDC cells, as indicated by two immunopositive spots seen in most of the nuclei. Both reactive species induced polymer accumulation in the HDCs. The PAR signal appeared rather homogeneously throughout the nuclei of peroxynitrite-treated cells (Fig. 5B and E). However, the staining pattern was slightly different in the hydrogen peroxide-treated cells. Hydrogen peroxide induced an increased nucleolar signal in the densely populated areas (Fig. 5C) and a homogeneous polymer accumulation in the loosely populated peripheral areas (Fig. 5F). Inhibition of PARP activity by $3-\mathrm{AB}$ fully prevented PAR accumulation without affecting the basal nucleolar signal (Fig. 5H and I).

\section{Discussion}

During differentiation or in the postmitotic phase, chondrocytes may be exposed to various degrees of oxidative stress. ROI and RNI are produced by chondrocytes as well as by infiltrating cells. Oxidative stress as defined by an imbalance of ROI/RNI production and antioxidant defense may cause cellular dysfunction or cell death and has been implicated in various pathological conditions such as chondrocyte senescence, osteoarthritis and mucopolysaccharidosis 

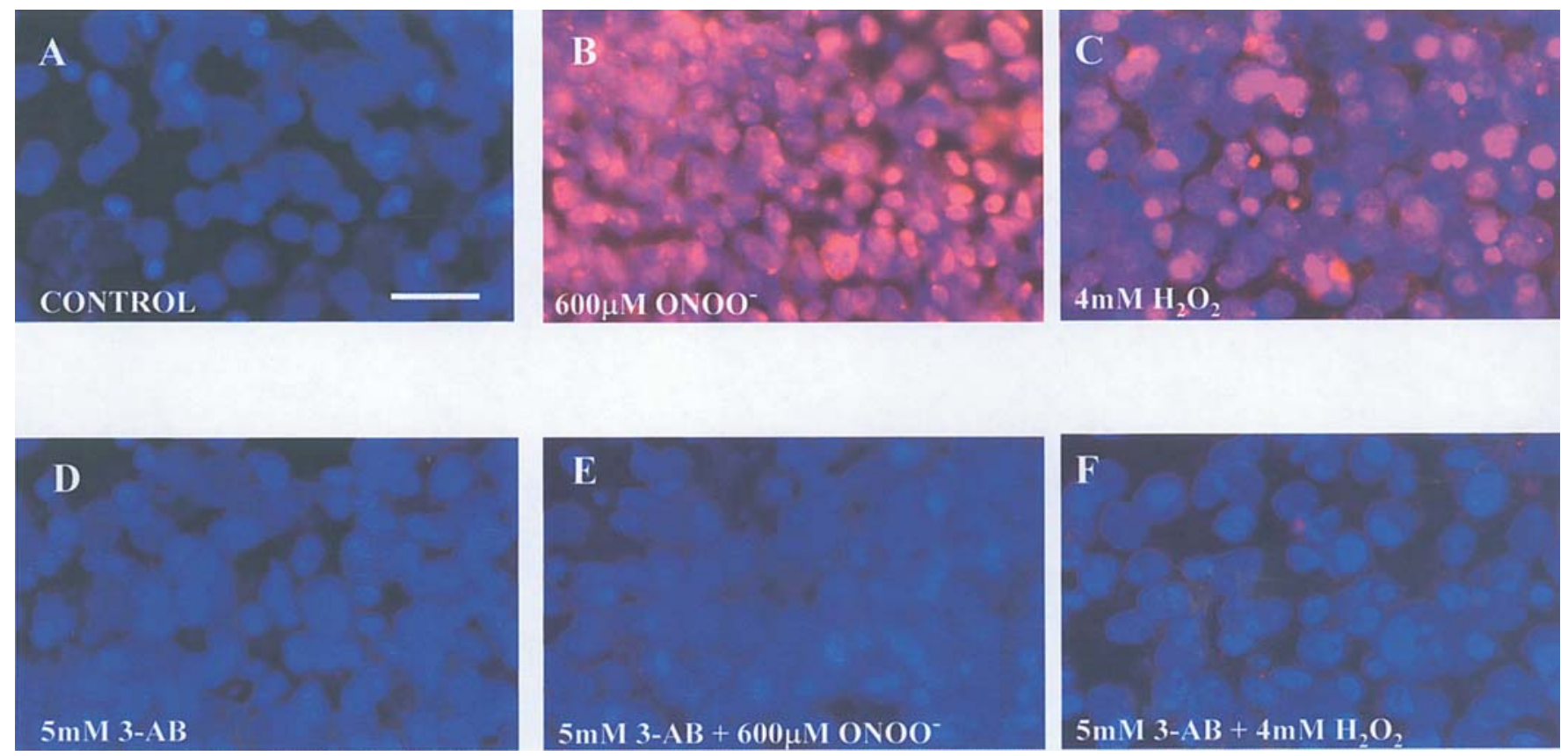

Figure 4. Oxidative stress stimulates PARP activity in HDCs. HDCs were exposed to the indicated concentrations of peroxynitrite or hydrogen peroxide. Some cultures were pretreated with 3-AB. Twenty min after oxidant exposure, PARP activity was detected by biotinyl-NAD incorporation. Nuclei were stained with $1 \mu \mathrm{g} / \mathrm{ml}$ DAPI. Pictures were taken with a Zeiss Axiolab microscope equipped with a Zeiss Axiocam digital camera. Exposure times were identical for all images. Images of PARP activity and DAPI were overlaid in Adobe Photoshop. Pre-treatment (30 min) with the PARP inhibitor 3-AB blocked PARP activity in peroxynitrite- (E) or hydrogen peroxide-treated (F) (20 min) HDCs. Bar, $30 \mu \mathrm{m}$.
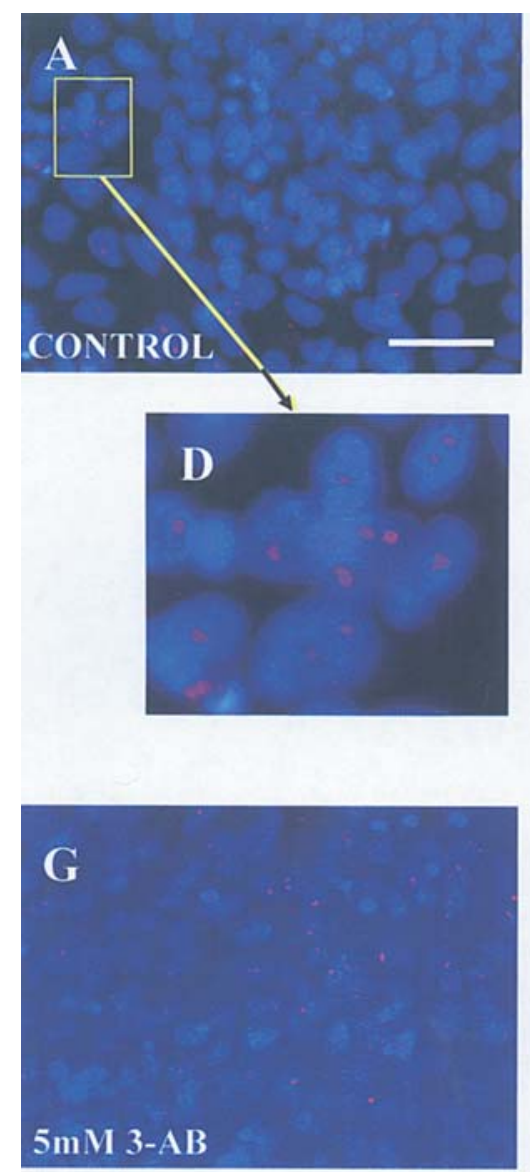
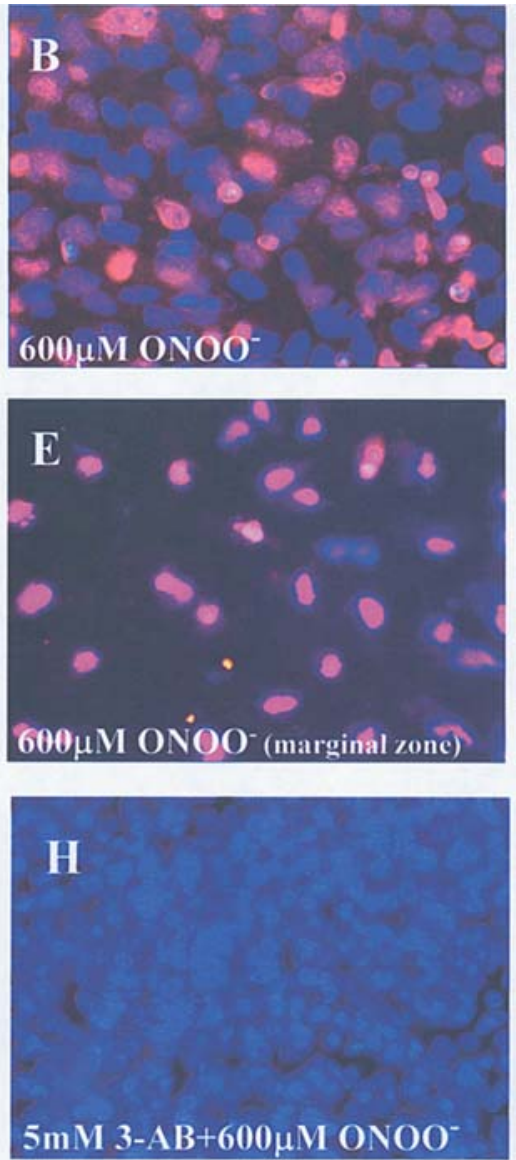
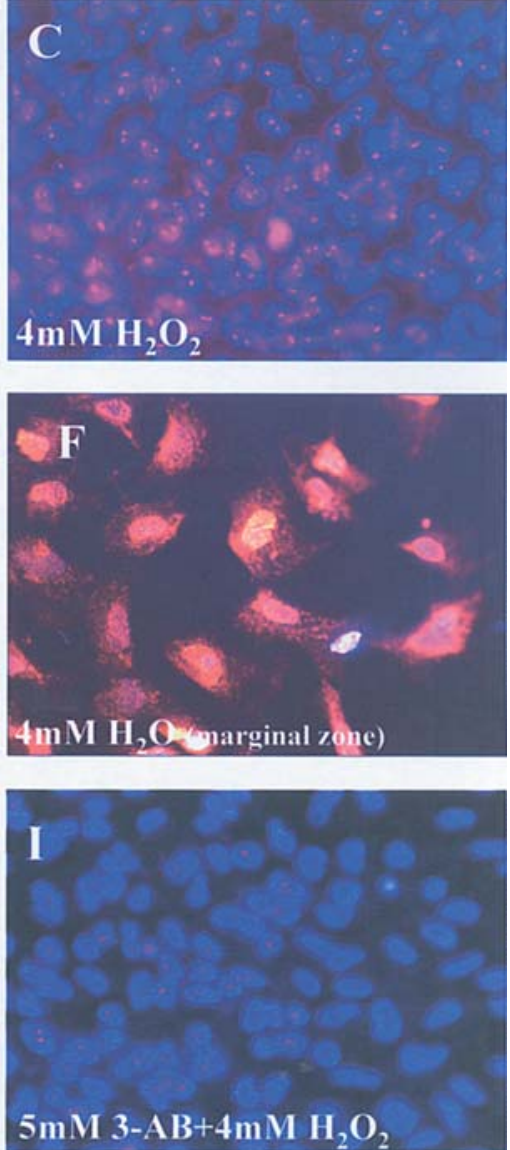

Figure 5. Oxidative stress-induced poly(ADP-ribose) accumulation in chondrocytes. HDCs were exposed to the indicated concentrations of peroxynitrite or hydrogen peroxide. Some cultures were pretreated with 3-AB. Twenty min after oxidant exposure, poly(ADP-ribose) accumulation was detected by immunocytochemistry. Nuclei were stained with $1 \mu \mathrm{g} / \mathrm{ml}$ DAPI. Pictures were taken with a Zeiss Axiolab microscope equipped with a Zeiss Axiocam digital camera. Exposure times were identical for all images. Images of PARP activity and DAPI were overlaid in Adobe Photoshop. Panel D is an enlarged area of panel A. Panels $\mathrm{E}$ and $\mathrm{F}$ show cells of the marginal area displaying strong immunopositivity for poly(ADP-ribose). Bar, $30 \mu \mathrm{m}$. 
$(14,15,35)$. Previous reports have suggested that many ROI and RNI species (e.g. hydrogen peroxide, peroxynitrite) inhibit proteoglycan synthesis and induce matrix degradation in cartilage $(19,36-38)$. In line with these reports, we demonstrated that hydrogen peroxide exerted a concentrationdependent suppression on matrix formation in HDCs. Similarly, peroxynitrite, one of the most reactive RNI species also inhibited matrix formation. The protective effect of the PARP inhibitor 3-AB implies that PARP activation may play a role in the oxidative stress-induced suppression of matrix formation. Indeed, we found that PARP activity was increased and poly(ADP-ribose) was accumulated in oxidatively stressed HDCs. These data suggest that hydrogen peroxide and peroxynitrite activate the 'DNA damage PARP activation - cell dysfunction' pathway.

With regard to the mechanism underlying the negative effect of oxidative stress and the beneficial effect of PARP inhibition, several possibilities should be considered. The 'PARP-mediated suicide hypothesis' first described by Berger et al proposed that oxidative stress induces DNA breakage leading to PARP activation (39). Excessive PARP activity depletes the substrate of the enzyme $\mathrm{NAD}^{+}$leading to a shutdown of cellular energy metabolism and eventually to cell dysfunction or cell death. Recently, alternative mechanisms have also been put forward to explain the role of PARP activation and cell death. Dawson's group has demonstrated that PARP activation can trigger the release of apoptosis-inducing factor (AIF) from the mitochondria to the nucleus thus leading to caspase-independent cell death (40). In our experiments, chondrogenic mesenchymal cells responded to hydrogen peroxide and peroxynitrite by a concentration-dependent inhibition of proliferation. Inhibition of proliferation appeared to be mediated by a PARP-independent mechanism, as indicated by the lack of effect of 3-AB. At higher concentrations of the oxidative stress agents, cell viability also decreased. PARP activation may be involved in oxidative stress-induced cell death of mesenchymal chondrogenic cells as $3-\mathrm{AB}$ provided significant protection. These findings are in accord with our previous observations demonstrating a PARP-independent inhibition of proliferation and a partially PARP-dependent cytotoxicity in oxidatively stressed HaCaT cells (41). Nonetheless, PARP-independent mechanisms also appear to play a clear role in the anti-proliferative and cytotoxic effect of hydrogen peroxide and peroxynitrite. Both oxidative species are known to cause direct damage in macromolecules in the form of protein oxidation, lipid peroxidation or nucleic acid modifications. Furthermore, ROI/RNI are capable of triggering signal transduction cascades (e.g. the MAP kinase pathway) mediating cell death $(42,43)$. These direct effects are likely to be involved in the deleterious effects of the reactive species. As for the PARP-dependent pathway, it did not display the characteristics of the classical Berger model as we observed no dramatically decreased cellular $\mathrm{NAD}^{+}$levels in oxidatively stressed HDCs. Although the highest concentrations of peroxynitrite and hydrogen peroxide caused $\mathrm{NAD}^{+}$depletion, this effect was only partially prevented by 3-AB. Therefore, PARP activation may contribute to chondrogenic cell dysfunction by triggering alternative mechanisms such as the MAP kinase route or the AIF- mediated caspase-independent apoptotic pathway. Further investigation is clearly needed to clarify the exact mechanism of oxidative stress-induced, PARP-independent cytotoxicity in this model. Nonetheless, our data indicate that cytotoxic mechanisms are not likely to be involved in the negative effect of oxidative stress on matrix production.

One notable novel finding was the presence of poly(ADPribose) in the nucleoli of unstimulated chick chondrogenic mesenchymal cells. Pretreatment of cells with $3-\mathrm{AB}$ had no effect on the nucleolar signal, indicating that these polymers were not synthesized during the 50-min duration of the experiment and that the turnover of these polymers is much slower compared to the polymers synthesized in response to DNA damage which have a half-life shorter than $1 \mathrm{~min}$. The presence of nucleolar poly(ADP-ribose) is consistent with the finding of Kasashima and Izawa (44) demonstrating poly(ADP-ribose) synthetic activity in isolated nucleoli from rapidly growing mouse ascite tumor cells. The specific activity of the synthesis in the nucleoli was significantly higher than that in the chromatin. The optimum magnesium and $\mathrm{NAD}^{+}$concentrations, and the effect of RNase treatment on the reaction in the nucleoli were also distinctly different from those in the chromatin. Our data also suggest a unique, nucleolar not yet fully characterized poly(ADP-ribose) signal present in HDCs. Interestingly, our in situ PARP activity assay did not detect ADP-ribose synthesizing activity in the nucleoli. This may either indicate that the nucleolar polymer is produced in a slow continuous synthetic process or may be due to the absence of nucleolar polymer degrading (PARG) activity. To note, $80-90 \%$ of cellular PARG activity is cytoplasmic in human cells (45). However, data on chicken cells with special regard to subnuclear distribution are not available.

The oxidative stress-induced PARP activation and poly(ADP-ribose) accumulation displayed a more homogeneous nuclear pattern with scattered cells in the periphery of the cultures showing stronger signals and cells in the central dense areas showing weaker activity. This observation is consistent with our previous findings demonstrating cell contact-mediated inhibition of oxidative stress-induced PARP-activation, caspase activation and cell death in $\mathrm{HaCaT}$ cells (46). Zaniolo et al (47) have also shown that the expression of PARP-1 is downregulated in dense cell cultures, a finding that may explain the low degree of polymer accumulation in such areas.

The most prominent finding of our current study is the role of poly(ADP-ribosyl)ation in the regulation of matrix production of HDCs. Previously published data were disparate with regard to the exact effect of poly(ADPribosyl)ation in the production of chondrogenic matrix. Midura et al reported reduced chondrogenesis in HDCs treated with the PARP inhibitors benzamide and nicotinamide (48). On the other hand, using benzamide as a PARP inhibitor, Nakanishi and Uyeki (26) found opposite effects in the same model. In our model, both hydrogen peroxide and peroxynitrite suppressed matrix formation in a $3-A B$ inhibitable manner. The beneficial effect of PARP inhibition may result from the improved cell viability of HDCs. However, the marked stimulatory effect of $3-\mathrm{AB}$ on the matrix formation of non-stressed cells indicates that 
poly(ADP-ribosyl)ation may play a more direct role in the synthesis of matrix components. PARP-1 has recently emerged as a transcriptional regulator involved in NFKB-, YY1-, Oct-1-, and p53-mediated transcription $(22,49,50)$. PARP-1 has also been implicated in nuclear receptor signaling (51). Moreover, expression of the Reg gene, the product of which is the key stimulator of pancreatic $B$ cell regeneration, has also been shown to be negatively regulated by auto-poly(ADP-ribosyl)ation of PARP-1 (52). Therefore, it appears likely that PARP activity suppresses the effect of key transcription factor(s) controlling the expression of matrix components. However, the exact nature of the role of poly(ADP-ribosyl)ation in the regulation of matrix production needs to be further investigated.

In summary, we demonstrated that oxidative stress stimulates poly(ADP-ribose) metabolism and inhibits extracellular matrix production of HDCs in a PARP-dependent manner. Furthermore, basal matrix production was found to be under the negative control of poly(ADP-ribosyl)ation. Our findings have implications for potential therapeutic approaches aimed at restoring the matrix production capacity of chondrogenic cells.

\section{Acknowledgements}

This study was supported by grants from the Hungarian Science Research Fund (nos. OTKA K60780 and K60620), the Hungarian Ministry of Health (nos. 083/2006 and 257/2006) and the MHSC-UD (DEOEC 06/2005). L.V. is supported by a Széchenyi fellowship from the Hungarian Ministry of Education.

\section{References}

1. Hall BK and Miyake T: Divide, accumulate, differentiate: cell condensation in skeletal development revisited. Int J Dev Biol 39: 881-893, 1995.

2. Cancedda R, Descalzi CF and Castagnola P: Chondrocyte differentiation. Int Rev Cytol 159: 265-358, 1995.

3. Sandell LJ and Adler P: Developmental patterns of cartilage. Front Biosci 4: D731-D742, 1999.

4. Ahrens PB, Solursh M and Reiter RS: Stage-related capacity for limb chondrogenesis in cell culture. Dev Biol 60: 69-82, 1977.

5. Hadhazy C, Lazlo MB and Kostenszky KS: Cartilage differentiation in micro-mass cultures of chicken limb buds. Acta Morphol Acad Sci Hung 30: 65-78, 1982.

6. DeLise AM, Fischer L and Tuan RS: Cellular interactions and signaling in cartilage development. Osteoarthritis Cartilage 8: 309-334, 2000.

7. Henrotin Y, Deby-Dupont G, Deby C, De Bruyn M, Lamy M and Franchimont P: Production of active oxygen species by isolated human chondrocytes. Br J Rheumatol 32: 562-567, 1993.

8. Hiran TS, Moulton PJ and Hancock JT: Detection of superoxide and NADPH oxidase in porcine articular chondrocytes. Free Radic Biol Med 23: 736-743, 1997.

9. Shingu M, Isayama T, Yasutake $C$, et al: Role of oxygen radicals and IL-6 in IL-1-dependent cartilage matrix degradation. Inflammation 18: 613-623, 1994.

10. Rathakrishnan C, Tiku K, Raghavan A and Tiku ML: Release of oxygen radicals by articular chondrocytes: a study of luminoldependent chemiluminescence and hydrogen peroxide secretion. J Bone Miner Res 7: 1139-1148, 1992.

11. Jouzeau JY, Pacquelet S, Boileau C, et al: Nitric oxide (NO) and cartilage metabolism: NO effects are modulated by superoxide in response to IL-1. Biorheology 39: 201-214, 2002.

12. Clancy R, Rediske J, Koehne C, et al: Activation of stressactivated protein kinase in osteoarthritic cartilage: evidence for nitric oxide dependence. Osteoarthritis Cartilage 9: 294-299, 2001.
13. Johnson K, Jung A, Murphy A, Andreyev A, Dykens J and Terkeltaub R: Mitochondrial oxidative phosphorylation is a downstream regulator of nitric oxide effects on chondrocyte matrix synthesis and mineralization. Arthritis Rheum 43: 1560-1570, 2000.

14. Tiku ML, Shah R and Allison GT: Evidence linking chondrocyte lipid peroxidation to cartilage matrix protein degradation. Possible role in cartilage aging and the pathogenesis of osteoarthritis. J Biol Chem 275: 20069-20076, 2000 .

15. Henrotin YE, Bruckner P and Pujol JP: The role of reactive oxygen species in homeostasis and degradation of cartilage. Osteoarthritis Cartilage 11: 747-755, 2003.

16. Hadjigogos $\mathrm{K}$ : The role of free radicals in the pathogenesis of rheumatoid arthritis. Panminerva Med 45: 7-13, 2003.

17. Haklar U, Yuksel M, Velioglu A, Turkmen M, Haklar G and Yalcin AS: Oxygen radicals and nitric oxide levels in chondral or meniscal lesions or both. Clin Orthop 403: 135-142, 2002.

18. Beckman JS and Koppenol WH: Nitric oxide, superoxide, and peroxynitrite: the good, the bad, and ugly. Am J Physiol 271: C1424-C1437, 1996.

19. Virág L, Szabó E, Gergely P and Szabó C: Peroxynitriteinduced cytotoxicity: mechanism and opportunities for intervention. Toxicol Lett 140-141: 113-124, 2003.

20. Radi R, Peluffo G, Alvarez MN, Naviliat M and Cayota A: Unraveling peroxynitrite formation in biological systems. Free Radic Biol Med 30: 463-488, 2001.

21. Virág L and Szabó C: The therapeutic potential of poly(ADPribose) polymerase inhibitors. Pharmacol Rev 54: 375-429, 2002.

22. Caplan AI, Niedergang C, Okazaki H and Mandel P: Poly(ADPribose) levels as a function of chick limb mesenchymal cell development as studied in vitro and in vivo. Dev Biol 72: 102-109, 1979.

23. Nishio A, Nakanishi S, Doull J and Uyeki EM: Enhanced chondrocytic differentiation in chick limb bud cell cultures by inhibitors of poly(ADP-ribose) synthetase. Biochem Biophys Res Commun 111: 750-759, 1983.

24. Cherney BW, Midura RJ and Caplan AI: Poly(ADP-ribose) synthetase and chick limb mesenchymal cell differentiation. Dev Biol 112: 115-125, 1985.

25. Nakanishi S and Uyeki EM: Benzamide on chondrocytic differentiation in chick limb bud cell culture. J Embryol Exp Morphol 85: 163-175, 1985.

26. Zakany R, Szues K, Bako E, et al: Protein phosphatase 2A is involved in the regulation of protein kinase A signaling pathway during in vitro chondrogenesis. Exp Cell Res 275: 1-8, 2002.

27. Modis L: Organization of the Extracellular Matrix. A Polarization Microscopic Approach. CRC Press, Boca Raton, FL, 1991.

28. Zakany R, Bako E, Felszeghy S, et al: Okadaic acid-induced inhibition of protein phosphatase $2 \mathrm{~A}$ enhances chondrogenesis in chicken limb bud micromass cell cultures. Anat Embryol 203: 23-34, 2001.

29. Mosmann T: Rapid colorimetric assay for cellular growth and survival: application to proliferation and cytotoxicity assays. J Immunol Methods 65: 55-63, 1983.

30. Burkle A, Chen G, Kupper JH, Grube K and Zeller WJ: Increased poly(ADP-ribosyl)ation in intact cells by cisplatin treatment. Carcinogenesis 14: 559-561, 1993.

31. Bakondi E, Bai P, Erdelyi K, et al: Detection of poly(ADPribose) polymerase activation in oxidatively stressed cells and tissues using biotinylated NAD substrate. J Histochem Cytochem 50: 91-98, 2002.

32. Bakondi E, Bai P, Erdelyi K, Szabó C, Gergely P and Virág L: Cytoprotective effect of gallotannin in oxidatively stressed HaCaT keratinocytes: the role of poly(ADP-ribose) metabolism. Exp Dermatol 13: 170-178, 2004.

33. Virág L, Scott GS, Cuzzocrea S, Marmer D, Salzman AL and Szabó C: Peroxynitrite-induced thymocyte apoptosis: the role of caspases and poly(ADP-ribose) synthetase (PARS) activation. Immunology 94: 345-355, 1998.

34. Simonaro CM, Haskins ME and Schuchman EH: Articular chondrocytes from animals with a dermatan sulfate storage disease undergo a high rate of apoptosis and release nitric oxide and inflammatory cytokines: a possible mechanism underlying degenerative joint disease in the mucopolysaccharidoses. Lab Invest 81: 1319-1328, 2001.

35. Dean RT, Roberts CR and Forni LG: Oxygen-centred free radicals can efficiently degrade the polypeptide of proteoglycans in whole cartilage. Biosci Rep 4: 1017-1026, 1984. 
36. Oh M, Fukuda K, Asada S, Yasuda Y and Tanaka S: Concurrent generation of nitric oxide and superoxide inhibits proteoglycan synthesis in bovine articular chondrocytes: involvement of peroxynitrite. J Rheumatol 25: 2169-2174, 1998.

37. Schalkwijk J, van den Berg WB, van de Putte LB and Joosten LA: Hydrogen peroxide suppresses the proteoglycan synthesis of intact articular cartilage. J Rheumatol 12: 205-210, 1985.

38. Fragonas E, Pollesello P, Mlinarik V, et al: Sensitivity of chondrocytes of growing cartilage to reactive oxygen species. Biochim Biophys Acta 1425: 103-111, 1998.

39. Berger NA, Sims JL, Catino DM and Berger SJ: Poly(ADPribose) polymerase mediates the suicide response to massive DNA damage: studies in normal and DNA-repair defective cells. Princess Takamatsu Symp 13: 219-226, 1983.

40. Yu SW, Wang H, Poitras MF, et al: Mediation of poly(ADPribose) polymerase-1-dependent cell death by apoptosisinducing factor. Science 297: 259-263, 2002.

41. Szabó E, Virag L, Bakondi E, et al: Peroxynitrite production, DNA breakage, and poly(ADP-ribose) polymerase activation in a mouse model of oxazolone-induced contact hypersensitivity. $\mathbf{J}$ Invest Dermatol 117: 74-80, 2001.

42. Asada S, Fukuda K, Nishisaka F, Matsukawa M and Hamanisi C: Hydrogen peroxide induces apoptosis of chondrocytes: involvement of calcium ion and extracellular signal-regulated protein kinase. Inflamm Res 50: 19-23, 2001.

43. Oh-Hashi K, Maruyama W, Yi H, Takahashi T, Naoi M and Isobe K: Mitogen-activated protein kinase pathway mediates peroxynitrite-induced apoptosis in human dopaminergic neuroblastoma SH-SY5Y cells. Biochem Biophys Res Commun 263: 504-509, 1999.

44. Kawashima K and Izawa M: Poly(ADP-ribose) synthesis in nucleoli and ADP-ribosylation of nucleolar proteins in mouse ascites tumor cells in vitro. J Biochem 89: 1889-1901, 1981.
45. Meyer-Ficca ML, Meyer RG, Coyle DL, Jacobson EL and Jacobson MK: Human poly(ADP-ribose) glycohydrolase is expressed in alternative splice variants yielding isoforms that localize to different cell compartments. Exp Cell Res 297: 521-532, 2004.

46. Bakondi E, Gonczi M, Szabo E, et al: Role of intracellular calcium mobilization and cell-density-dependent signaling in oxidative-stress-induced cytotoxicity in HaCaT keratinocytes. J Invest Dermatol 121: 88-95, 2003.

47. Zaniolo K, Rufiange A, Leclerc S, Desnoyers S and Guerin SL: Regulation of the poly(ADP-ribose) polymerase-1 gene expression by the transcription factors $\mathrm{Sp} 1$ and $\mathrm{Sp} 3$ is under the influence of cell density in primary cultured cells. Biochem $\mathbf{J}$ 389: 423-433, 2005.

48. Midura RJ, Cherney BW and Caplan AI: The relationship of nicotinamide adenine dinucleotide to the chondrogenic differentiation of limb mesenchymal cells. Dev Biol 111: 232-242, 1985.

49. Hassa PO and Hottiger MO: A role of poly(ADP-ribose) polymerase in NF-kappaB transcriptional activation. Biol Chem 380: 953-959, 1999.

50. Oliver FJ, Menissier-de Murcia J, Nacci C, et al: Resistance to endotoxic shock as a consequence of defective NF-kappaB activation in poly (ADP-ribose) polymerase-1 deficient mice. EMBO J 18: 4446-4454, 1999.

51. Miyamoto $\mathrm{T}$, Kakizawa $\mathrm{T}$ and Hashizume K: Inhibition of nuclear receptor signalling by poly(ADP-ribose) polymerase. Mol Cell Biol 19: 2644-2649, 1999.

52. Akiyama T, Takasawa S, Nata K, et al: Activation of Reg gene, a gene for insulin-producing beta-cell regeneration: poly(ADPribose) polymerase binds Reg promoter and regulates the transcription by autopoly(ADP-ribosyl)ation. Proc Natl Acad Sci USA 98: 48-53, 2001. 